Aim of the study: Malignant breast tumours are the largest oncological problem in the developed world. In the recent years the number of new diagnoses has exceeded 16,500 per year. Published data regarding far-distant results of breast cancer treatment that take under consideration the provincial division of the country may not be representative of the therapeutic effects achieved in specific oncological centres. The goal of this article is to analyse far-distant therapeutic results in breast cancer patients treated at the Oncology Centre in Bydgoszcz in 2006. They were compared with data available for Kujawsko-Pomorskie Voivodeship and with all-Poland results.

Material and methods: A cohort of 667 breast cancer patients at Bydgoszcz Oncology Centre between Jan 1 and Dec 31, 2006 was studied. The majority of the studied group were patients in stage I (26.2\%) and II (48.3\%) according to the TNM staging system, $17.5 \%$ were in stage III, and $6.4 \%$ in stage IV. The 5 -year survival and 5 -year disease-free survival rates were calculated. Median observation time was 79 months.

Results: A total of 148 patients $(22.2 \%)$ suffered a relapse. There were 168 (25.2\%) deaths caused by primary disease. The 5 -year survival probability was $0.761 \pm 0.017$ and the five-year disease-free survival probability was $0.807 \pm 0.016$. Median survival time was 76.4 months, and median disease-free survival was 19.4 months. Conclusions: The five-year survival probability for breast cancer patients undergoing treatment at Bydgoszcz Oncology Centre was higher than all-Poland median five-year survival probability. The observation needs to be continued and should include the assessment of treatment in subsequent time periods.

Key words: breast cancer, 5-year survival rate, treatment outcomes, treatment patterns, mortality.

Contemp Oncol (Pozn) 2015; 19 (4): 284-289 DOI: $10.5114 /$ wo.2015.54387

\section{Overall survival and disease-free survival in breast cancer patients treated at the Oncology Centre in Bydgoszcz - analysis of more than six years of follow-up}

Tomasz Nowikiewicz ${ }^{1}$, Magdalena Wiśniewska², Michał Wiśniewski ${ }^{3}$, Marta Biedka ${ }^{4}$, Iwona Głowacka ${ }^{5}$, Dominika Kozak ${ }^{5}$, Ryszard Laskowski ${ }^{1}$, Wojciech Zegarski ${ }^{5}$

${ }^{1}$ Clinical Department of Breast Cancer and Reconstructive Surgery, Oncology Centre, Bydgoszcz, Poland

${ }^{2}$ Department of Clinical Oncology, Oncology Centre, Bydgoszcz, Poland

${ }^{3}$ Ambulatory of Chemotherapy, Oncology Centre, Bydgoszcz, Poland ${ }^{4}$ Department of Radiotherapy II, Oncology Centre, Bydgoszcz, Poland

${ }^{5}$ Surgical Oncology Clinic, Collegium Medicum in Bydgoszcz, Nicolaus Copernicus University in Torun, Oncology Centre, Bydgoszcz, Poland

\section{Introduction}

Breast cancer is the leading cause of malignant tumours among Polish women [1]. A similar phenomenon is observed in other developed countries [2]. According to all-Poland data, the 5-year prevalence of breast cancer among women (the proportion of a population found to have a condition within 5 years preceding that year) was $30.5 \%$ of total malignant cancer cases. It translated to almost 53,500 patients [3].

In 2010 there were 15,981 new diagnoses (including 15,784 female cases); this was $22.4 \%$ of total cancer diagnoses among female patients and caused $12.8 \%$ of deaths within that group [1].

At that time there were 864 new cases of breast cancer reported for female patients in the Kujawsko-Pomorskie Voivodeship [1]. According to National Health Fund (NFZ) data, the number of cases in 2004-2010 was practically unchanged compared to a slow growth tendency observed in Poland [4]. In 2010 there were 303 deaths caused by malignant breast cancer. The standardised malignant breast cancer incidence rate was slightly higher in Kujawsko-Pomorskie Voivodeship than the one calculated for the whole country $\left(51.3 / 10^{5}\right.$ vs. $\left.49.6 / 10^{5}\right)$. Standardised mortality rate was $14.8 / 10^{5}$, exceeding the average rates calculated for the whole country and higher than results of the majority of other voivodeships [1].

Published data regarding far-distant results of breast cancer treatment that take the provincial division of the country under consideration may not be representative of the therapeutic effects achieved in specific oncological centres. This is a result of the lack of possibility to provide treatment for all patients in the region by one medical unit and the option for patients to seek treatment outside of their place of residence.

The goal of this article is to analyse far-distant therapeutic results in breast cancer patients treated at the Oncology Centre in Bydgoszcz in 2006. They were compared with data available for Kujawsko-Pomorskie Voivodeship and with all-Poland results. 


\section{Material and methods}

A cohort of 667 malignant breast cancer patients who started oncological treatment at Bydgoszcz Oncology Centre between Jan 1 and Dec 31, 2006 was studied. Patients analysed were the those who had not been diagnosed with breast cancer before and had not received any medical treatment for that reason. All patients meeting the above criteria were taken under consideration independently of the kind of treatment they were receiving.

The analysis did not include patients who in our Centre had continued supplemental breast cancer treatment that was started before in another medical unit (e.g. supplemental radiotherapy cases after breast-conserving surgery in another medical unit, cases of continued systemic treatment, singular therapeutic consultation during a treatment conducted in another unit). Patients treated in 2006 due to relapse of a previously diagnosed cancer were also excluded.

Clinical material was retrospectively studied in order to analyse the kinds of treatment ordered for patients and the reasons behind qualifying patients for various forms of therapy. Affiliation of patients to specific voivodeship branches of the National Health Fund (NFZ) was also defined (Table 1). Median observation time was 79 months (range: 4-96 months).

\section{Statistical analysis}

Data pertaining to the course of disease and treatment results was collected from medical documentation of Bydgoszcz Oncology Centre and transformed into a database in Microsoft Office Excel (version 2007). Additionally, IBM SPSS Statistics (version 21.0) software was used for the purpose of statistical analysis.

The following rates were calculated using Mantel-Cox method: overall 5-year survival (pOS), disease-free survival probability (pDFS) in the group of surgically treated patients, and the progression-free 5 -year survival (pPFS) in the group of patients treated conservatively. Results were expressed graphically in the form of Kaplan-Meier curves. The results between comparable patient groups were statistically significant with a $P$ value of less than 0.05 .

\section{Results}

The vast majority of evaluated patients were women - 664 (99.6\%). The average age of the patients was 57.7 \pm 12.2 years (range $27-94$ years). In the case of patients qualified for surgical treatment the average age was significantly statistically lower, at $56.4 \pm 11$.4 years (range $27-$ 87 years), when compared to the age in the group of patients receiving conservative treatment $(64.9 \pm 13.8$ years, range 34-94 years; $p<0.001$ ).

Table 1. Breast cancer patients treated at Bydgoszcz Oncology Center in 2006 - type of anti-cancer treatment ordered

\begin{tabular}{|c|c|c|c|}
\hline Type of treatment & $\begin{array}{c}\text { Number of patients } \\
\text { (NFZ - all branches) } \\
n(\%)\end{array}$ & $\begin{array}{c}\text { Number of patients } \\
\text { (NFZ - } 02-\text { Kujawsko-Pomorskie } \\
\text { Voivodeship) } \\
n(\%)\end{array}$ & $\begin{array}{c}\text { Number of patients } \\
\text { (NFZ - other branches) } \\
n(\%)\end{array}$ \\
\hline $\begin{array}{l}\text { Surgical treatment } \\
\text { radical } \\
\text { non-radical }\end{array}$ & $\begin{array}{c}567(85.0) \\
553(97.5) \\
14(2.5)\end{array}$ & $\begin{array}{c}501(88.4) \\
488(88.2) \\
13(92.9)\end{array}$ & $\begin{array}{c}66(11.6) \\
65(11.8) \\
1(7.1)\end{array}$ \\
\hline Non-surgical approach & $100(15.0)$ & $90(90.0)$ & $10(10.0)$ \\
\hline Total & $667(100)$ & $591(88.6)$ & $76(11.4)$ \\
\hline
\end{tabular}

Table 2. Breast cancer patients treated at Bydgoszcz Oncology Centre in 2006 - primary tumour size (cT) and TNM Classification of Malignant Tumours

\begin{tabular}{|c|c|c|c|}
\hline $\begin{array}{l}\text { Primary tumour size (cT) - TNM } \\
\text { classification }\end{array}$ & $\begin{array}{l}\text { All patients } \\
n(\%)\end{array}$ & $\begin{array}{l}\text { Surgical treatment } \\
\qquad n(\%)\end{array}$ & $\begin{array}{c}\text { Non-surgical treatment } \\
n(\%)\end{array}$ \\
\hline $\mathrm{CT} 1$ & 207 (31.0) & $201(35.4)$ & $6(6.0)$ \\
\hline CT2 & $300(45.0)$ & $280(49.4)$ & $20(20.0)$ \\
\hline CT3 & $32(4.8)$ & $20(3.5)$ & 12 (12.0) \\
\hline CT4 & 115 (17.2) & $56(9.9)$ & $59(59.0)$ \\
\hline CTx & $13(1.9)$ & $10(1.8)$ & $3(3.0)$ \\
\hline \multicolumn{4}{|l|}{$\begin{array}{l}\text { Stage according to TNM staging } \\
\text { system }\end{array}$} \\
\hline 1 & $175(26.2)$ & $171(30.2)$ & $4(4.0)$ \\
\hline$\|$ & $322(48.3)$ & $306(54.0)$ & $16(16.0)$ \\
\hline III & 117 (17.5) & 79 (13.9) & $38(38.0)$ \\
\hline IV & $43(6.4)$ & $1(0.2)$ & $42(42.0)$ \\
\hline nd & $10(1.5)$ & $10(1.8)$ & $0(0)$ \\
\hline Total & 667 (100) & 567 (100) & 100 (100) \\
\hline
\end{tabular}




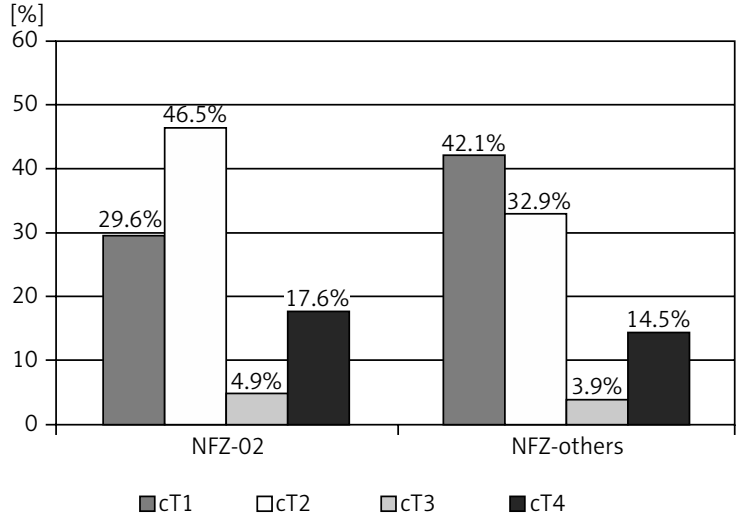

Fig. 1. Primary tumour size (cT) and TNM Classification of Malignant Tumours classification depending on place of patient's residence

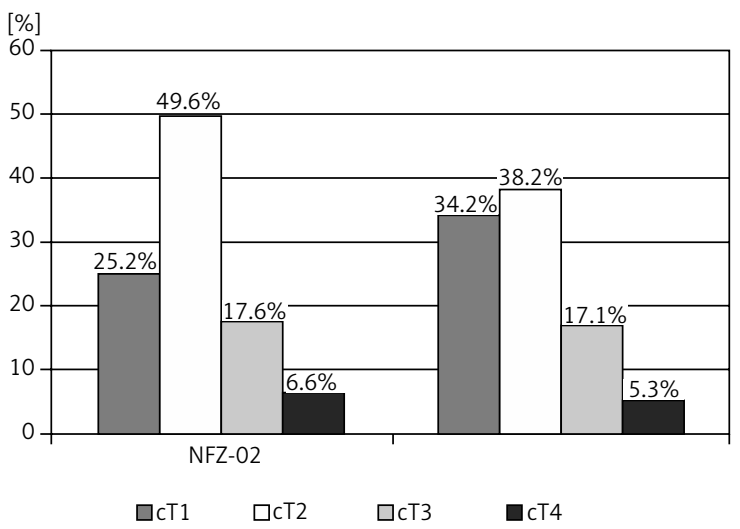

Fig. 2. Primary tumour size (cT) and TNM Classification of Malignant Tumours classification depending on place of patient's residence

Table 3. Surgically treated breast cancer patients - histopathology results

\begin{tabular}{|c|c|c|}
\hline $\begin{array}{l}\text { Histopathological assessment } \\
\text { of the tumour - pT }\end{array}$ & $\begin{array}{l}\text { Number of patients - } \\
\text { surgical treatment }\end{array}$ & $\%$ \\
\hline pTO & 12 & 2.1 \\
\hline pTis & 18 & 3.2 \\
\hline $\begin{array}{l}\text { PT1 } \\
1 \mathrm{mic} \\
1 \mathrm{a} \\
1 \mathrm{~b} \\
1 \mathrm{c}\end{array}$ & $\begin{array}{c}250 \\
3 \\
11 \\
56 \\
180\end{array}$ & $\begin{array}{c}44.1 \\
0.5 \\
1.9 \\
9.9 \\
31.7\end{array}$ \\
\hline pT2 & 226 & 39.9 \\
\hline pT3 & 24 & 4.2 \\
\hline pT4 & 20 & 3.5 \\
\hline pTx & 17 & 3.0 \\
\hline \multicolumn{3}{|l|}{$\begin{array}{l}\text { Histopathological assessment } \\
\text { of the lymphatic nodes - pN }\end{array}$} \\
\hline pNO & 294 & 51.9 \\
\hline pNO(i+) & 2 & 0.4 \\
\hline pN1mi & 18 & 3.2 \\
\hline pN1a & 93 & 16.4 \\
\hline pN2a & 76 & 13.4 \\
\hline pN3a & 67 & 11.8 \\
\hline $\mathrm{pNx}$ & 17 & 3.0 \\
\hline
\end{tabular}

The majority of the analysed group were patients in stage | (26.2\%) and stage || (48.3\%) according to TNM staging system. The remaining patients were in stage III - $17.5 \%$, and stage IV $-6.4 \%$. The degree of cancer advancement was significantly statistically different when comparing groups of patients treated surgically and conservatively. Similar differences were found when analysing the size of primary tumour in the clinical trial $(p<0.001$ Table 2).

Figures 1 and 2 compare the size of primary tumours and degree of cancer advancement - evaluated in a clinical trial, diagnosed in a group of patients residing in Kujawsko-Pomorskie Voivodeship and in the areas of other NFZ branches.

The vast majority of analysed patients were treated surgically (85\%, 567 patients). In the remaining cases the reason for the lack of surgical treatment was the presence of distant metastases, baseline unresectability of the tumour with unsuccessful induction treatment, and circumstances disqualifying the patient from undergoing general anaesthesia (respectively: $41 \%, 34 \%$, and $16 \%$ of cases).

Histopathology of surgically removed tumours indicated the presence of invasive cancer in $96.8 \%$ of cases. In $67.4 \%$ of cases it was ductal carcinoma, $8.1 \%$ lobular carcinoma, and the remaining $8.1 \%$ consisted of other histopathological types of invasive carcinoma. In the majority of cases of patients operated after induction, histopathology of removed tumours did not include detailed data other than describing the invasive character of the tumour (13.2\% of surgically treated patients). In total $3.2 \%$ of the patients were diagnosed with ductal carcinoma in situ

Table 4. Overall five-year survival (pOS) rate in the group of breast cancer patients treated at Bydgoszcz Oncology Centre in 2006, depending on the disease stage

\begin{tabular}{cccccc} 
Disease stage & Number & Number & \multicolumn{2}{c}{ Cut } \\
\cline { 5 - 6 } $\begin{array}{c}\text { according to TNM } \\
\text { staging system }\end{array}$ & $\begin{array}{c}\text { of } \\
\text { patients }\end{array}$ & $\begin{array}{c}\text { of cases } \\
\text { (death) }\end{array}$ & $n$ & $\%$ \\
I & 175 & 6 & 169 & 96.6 \\
II & 322 & 51 & 271 & 84.2 \\
III & 117 & 68 & 49 & 41.9 \\
IV & 43 & 43 & 0 & 0.0 \\
Total & 657 & 168 & 489 & 74.4
\end{tabular}

Table 5. Disease-free survival probability (pDFS) rate in the group of breast cancer patients treated at Bydgoszcz Oncology Centre in 2006, depending on the disease stage

\begin{tabular}{ccccc} 
Disease stage & Number & Number of & \multicolumn{2}{c}{ Cut } \\
\cline { 5 - 6 } $\begin{array}{c}\text { according to TNM } \\
\text { staging system }\end{array}$ & $\begin{array}{c}\text { of } \\
\text { patients }\end{array}$ & $\begin{array}{c}\text { cases (disease } \\
\text { recurrence) }\end{array}$ & $n$ & $\%$ \\
I & 174 & 10 & 164 & 94.3 \\
II & 322 & 53 & 269 & 83.5 \\
III & 117 & 56 & 61 & 52.1 \\
Total & 43 & 29 & 14 & 32.6 \\
\hline
\end{tabular}




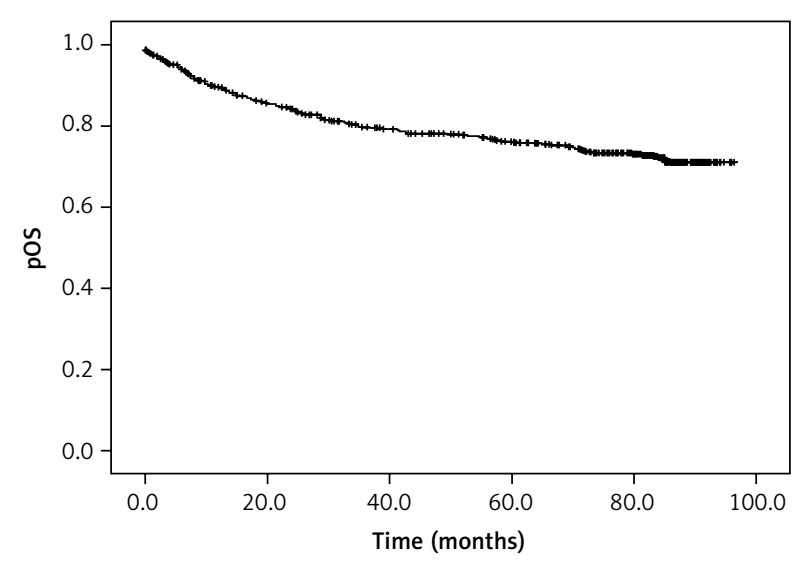

Fig. 3. Overall five-year survival (pOS) rate in the group of breast cancer patients treated at Bydgoszcz Oncology Centre in 2006

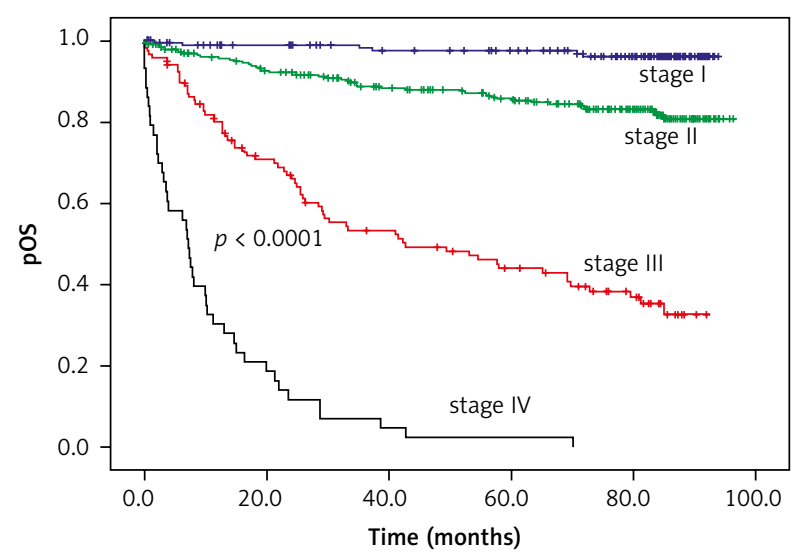

Fig. 5. Overall five-year survival (pOS) rate in the group of breast cancer patients depending on the disease stage

(DCIS). Data regarding the size of primary tumours and the condition of armpit lymph nodes from pathological reports is presented in Table 3 (the chart includes results of histopathology testing of patients following induction treatment).

A total of 148 patients (22.2\%) had suffered a relapse. There were 168 (25.2\%) deaths caused by primary disease. The 5-year survival probability calculated for the whole analysed group of patients was $0.761 \pm 0.017$ (Fig. 3), and the 5-year disease-free survival probability was $0.807 \pm 0.016$ (Fig. 4). Median survival time was 76.4 months, and median disease-free survival was 19.4 months.

In the group of surgically treated patients there was a relapse in 95 (16.8\%) of cases. There were 76 (13.4\%) deaths. Median survival time was 80.3 months, and median disease-free survival was 24.4 months. The 5-year survival probability was $0.886 \pm 0.014$, and the 5 -year disease-free survival probability was $0.880 \pm 0.014$.

In the group of conservatively treated patients there was relapse in 57 (57\%) of cases. There were 92 (92\%) deaths. The 5-year survival probability was $0.091 \pm 0.029$,

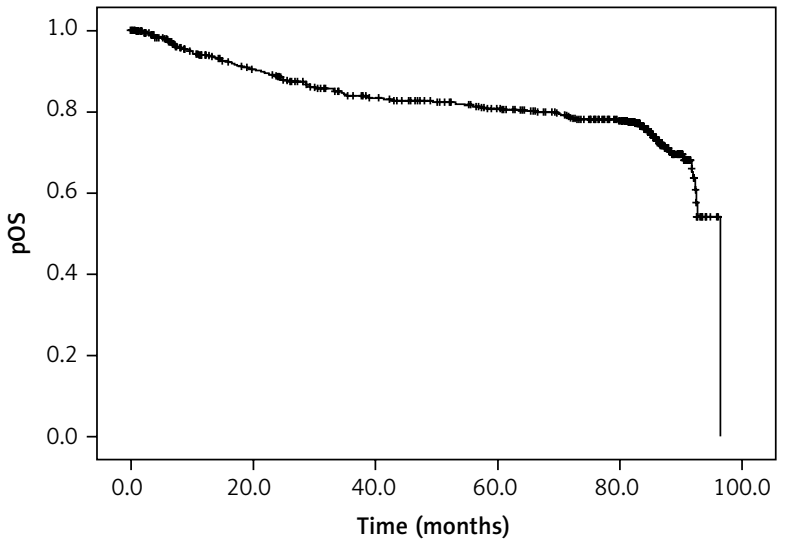

Fig. 4. Disease-free survival probability (pDFS) rate in the group of breast cancer patients treated at Bydgoszcz Oncology Centre in 2006

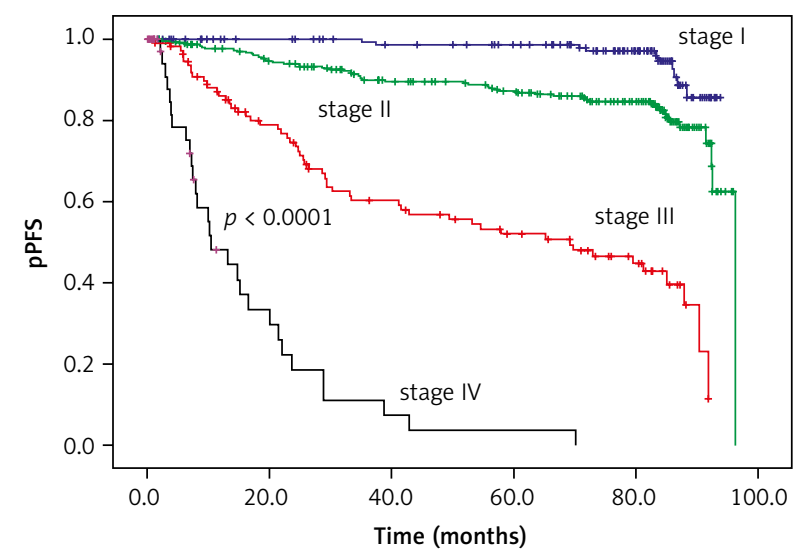

Fig. 6. Disease-free survival probability (pDFS) rate in the group of breast cancer patients depending on the disease stage

and the 5-year disease-free survival probability was 0.193 \pm 0.051 .

Survival probability rates were also calculated depending on the stage of the disease (there was a lack of necessary data in 10 cases). The 5 -year survival probability for stage I was $0.975 \pm 0.012$, for stage II it was $0.856 \pm 0.021$, for stage III it was $0.440 \pm 0.049$, and for stage IV it was $0.023 \pm 0.023$ (Table 4, Fig. 5). The 5-year disease-free survival probability for stage I was $0.987 \pm 0.009$, for stage II it was $0.873 \pm 0.020$, for stage III it was $0.520 \pm 0.052$, and for stage IV it was $0.037 \pm 0.036$ (Table 5 , Fig. 6). In both of the described cases the results between compared patient groups were statistically significant with a $p$ value of less than 0.0001 .

\section{Discussion}

The incidence of malignant breast cancer has been systematically growing in Poland. According to epidemiological prognosis we can expect its further growth up to around 19,500-20,500 new cases in 2019 [5]. As well as all-country summaries there are prognoses being creat- 
ed for specific voivodeships, predicting the development of a similar situation in the near future [6]. Despite this tendency, the observed results of treatment are improving. According to data of the National Cancer Registry there was a growth of relative 5-year survival - from 75\% in 2000-2002 to $77.2 \%$ in 2003-2005 [1, 7].

The 5-year survival rate in 2006, when calculated based on data published by Kozierkiewicz et al., was a bit lower and amounted to 73\%. However, independently of the rates, far-distant results of treatment in individual regions of the country are noticeably different. Results achieved in Kujawsko-Pomorskie Voivodeship in the above-mentioned time period (five-year survival rate of $70 \%$ ) are among the lowest in Poland [8]. Consequently, they are much lower than those indicated by our clinical material (76.1\%).

According to data of the Centre of Epidemiology and Prevention Department of Warsaw Oncology Centre, the average age of breast cancer incidence in Poland (during 2003-2005) was 59 years [9]. Therefore, it was higher (without statistically significant differences) than that calculated for patients treated at our centre (57.7 years, and in the case of the surgically treated group -56.4 years).

According to data presented by Didkowska and Wojciechowska, $4 \%$ of the new incidents of malignant breast tumours diagnosed in 2006 were patients in stage 0 (in situ carcinomas). Patients in local stage constituted $51 \%$ of the total, regional $-37 \%$, and those with distant metastases $-8 \%$ of the cases [2]. In the analysed group of patients the proportion of those in local stage at the moment of diagnosis was significantly lower and amounted to $46 \%$ of the cases. The proportion of patients in regional stage was a lot higher than that mentioned above (with metastases to surrounding lymph node groups in $45 \%$ of the patients). Both of these features - the size of primary tumour and the condition of regional lymph nodes - are some of the most important prognostic factors in cases of breast cancer [10]. Therefore, the fact that those differences existed could directly affect the far-distant treatment results we have observed.

The number of patients qualified for supplemental radiotherapy also confirms the serious advancement of disease. In 2006 in Kujawsko-Pomorskie Voivodeship it was ordered for almost half of breast cancer patients (the Oncology Centre in Bydgoszcz was the only medical unit in the voivodeship that allowed for such treatment at that time). Radiotherapy was mostly prescribed to patients who needed to be treated with radiation due to poor prognosis. Only a small proportion of patients were receiving radiotherapy as part of conservative treatment. This proportion was one of the highest in the country (second place after Zachodniopomorskie Voivodeship) [4].

In the analysed clinical material $85 \%$ of the patients were treated surgically. The proportion of surgical treatment is comparable to all-country data (in 2006 it was about $83 \%)[4,7]$ and much higher than the proportion for the whole of Kujawsko-Pomorskie Voivodeship (78.6\%) [7]. Kozierkiewicz et al. showed that this proportion grew in Poland from $77 \%$ in 2004 to $90 \%$ in 2010 [4].

According to data presented by the National Oncological Surgery Consultant, the vast majority of malignant breast cancer patients, unlike gastrointestinal tumour patients (90\% vs. 40\%), in 2010 were treated surgically (in the form of planned resective surgeries) at oncological surgery departments [11]. We do not currently have at our disposal similar data pertaining to the analysed time period (2006). However, as underlined by the author, (...) the chances of Polish oncological patients being cured vary depending on their place of residence, the medical unit conducting the treatment, and the specialisation of the doctor [11]. The importance of the experience of the operating surgeon, when it comes to far-distant cancer treatment results achieved, is also confirmed by other authors [7, 12].

Another factor that could affect the far-distant cancer treatment results achieved in individual country regions is the degree of utilisation of mammography screening. In 2007 a higher proportion of this exam in diagnostics that preceded the treatment correlated with better treatment results [7]. In Kujawsko-Pomorskie Voivodeship it was conducted on $23.6 \%$ of breast cancer patients. This proportion was much smaller than in other voivodeships (up to $40.3 \%$ of the cases in Lubuskie Voivodeship) and the all-country median (28\%) [7].

Despite the presence of regional differences when it comes to far-distant breast cancer treatment results in Poland, mammography screening has not yet affected the total survival rate of the patients [7]. However, there are noticeable positive effects of its implementation, mainly in the form of a statistically significant increase in the possibility to utilise the conservative treatment - both for breast glands and axillary lymph nodes [13].

It seems reasonable to include the place of residence in the assessment of treatment results achieved in individual oncological centres. Changing the permanent residence address (including the voivodeship) applies to $0.18 \%$ of the breast cancer patient population in Poland. On the other hand, about $17 \%$ of those patients have at least once during the treatment undergone a part of it in another NFZ branch [8].

Over $11 \%$ of our patients receiving malignant breast tumour treatment in 2006 had permanently resided outside of the Kujawsko-Pomorskie Voivodeship area. Compared to the residents of our region they were a group of patients with lower clinical and pathological (statistically insignificant differences) advancement of the disease. This fact can additionally explain the differences between the treatment results of the analysed group of patients.

According to the opinion of some of the authors, the quality of achieved treatment results can indirectly depend on public health spending $[8,11]$. Kujawsko-Pomorskie Voivodeship belongs to a group of regions with a relatively low 5-year survival rate of breast cancer patients and at the same time with low treatment expenditure [8]. This could mean that increasing the spending would allow for improvement of the analysed rates.

In conclusion, the 5-year survival probability for breast tumour patients undergoing treatment at Bydgoszcz Oncology Centre was higher than the median probability for Kujawsko-Pomorskie Voivodeship and for the whole country. The far-distant results of the treatment very much depend on the time of diagnosis, and the differences noted 
within that extent among the groups of patients with various degree of tumour advancement are statistically significant. The results we presented indicate the importance of continuing observation, also taking into consideration the treatment of other patients in different time periods.

The authors declare no conflict of interest.

\section{References}

1. Wojciechowska U, Didkowska J. Cancer in Poland in 2012. Nowotwory J Oncol 2013; 63: 197-216.

2. Didkowska J, Wojciechowska U. Breast cancer in Poland and Europe - population and statistics. Nowotwory J Oncol 2013; 63: 111-8.

3. Didkowska J, Wojciechowska U. Number of patients with diagnosed malignant diseases in Poland in 2006 - five-year prevalence. Nowotwory J Oncol 2011; 61: 332-5.

4. Kozierkiewicz A, Śliwczyński A, Jassem J, Topór-Mądry R, Paszkiewicz J. Breast cancer treatment patterns in Poland. Nowotwory J Oncol 2012; 62: 250-62.

5. Wojtyś P, Godlewski D, Andrzej Antczak A. Predictions of cancer incidence in Poland in 2019. Cent Eur J Med 2013; 8: 185-91.

6. Godlewski D, Wojtyś P, Antczak A. Predictions of cancer incidence in Wielkopolska in 2018. Contemp Oncol 2012; 16: 38-43.

7. Herman K, Śliwczyński A, Wysocki WM. Breast cancer treatment outcomes, therapy options and costs in Poland (2005-2007). Nowotwory J Oncol 2014; 64: 33-9.

8. Kozierkiewicz A, Topór-Mądry R, Śliwczyński A, Pakulski M, Jassem 」. Effectiveness and costs of breast cancer therapy in Poland: a regional approach. Nowotwory J Oncol 2014; 64: 24-32.

9. Wojciechowska U, Didkowska J. Improvement in survival of cancer patients in Poland: analysis of survival of patients diagnosed 2003-2005. Nowotwory J Oncol 2013; 63: 279-85.

10. Donegan WL. Tumor-related prognostic factors for breast cancer. CA Cancer Clin J 1997; 47: 28-51.

11. Herman K. The status of surgical oncology in Poland: the 2010 perspective. Nowotwory J Oncol 2011; 61: 315-25.

12. Kingsmore D, Hole D, Gillis C. Why does specialist treatment of breast cancer improve survival? The role of surgical management. Br J Cancer 2004; 90: 1920-25.

13. Nowikiewicz T, Zegarski W, Piątkowska M, Klag M. Evaluation of the effects of mammography screening program on cancer progression and implemented treatment in patients with breast cancer. Pol Przegl Chir 2013; 85: 367-77.

\section{Address for correspondence}

\section{Tomasz Nowikiewicz}

Clinical Department of Breast Cancer and Reconstructive Surgery

Oncology Centre

Romanowskiej 2

85-796 Bydgoszcz, Poland

e-mail: tomasz.nowikiewicz@gmail.com

Submitted: 3.11 .2014

Accepted: 19.11.2014 